\title{
Our Experience in Osteoid Osteoma Patients Treated with Computed Tomography Guided Percutaneous Radiofrequency Ablation
}

\section{Osteoid Osteoma Olgularımızın Bilgisayarlı Tomografi Rehberliğinde Radyofrekans Ablasyon ile Tedavisi}

\author{
Namık Kemal Altınbaş̧ ${ }^{1}$, Cemil Yağcı ${ }^{1}$, Kerem Başarır ${ }^{2}$ \\ ${ }^{1}$ Ankara Üniversitesi Tıp Fakültesi, Radyoloji Ana Bilim Dalı, Ankara \\ ${ }^{2}$ Ankara Üniversitesi Tıp Fakültesi, Ortopedi ve Travmatoloji Ana Bilim Dalı, Ankara
}

Dergiye Ulaşma Tarihi 07.04.2016: Dergiye Kabul Tarihi:18.04.2016 DOI: 10.5505/aot.2016.08108

\begin{abstract}
ÖZET
Amaç: Günümüzde osteoid osteoma olgularında bilgisayarlı tomografi (BT) rehberliğinde perkütan radyofrekans (RF) ablasyon tedavisi popular bir yöntem olarak uygulanmaktadır. Bu çalışmanın amacı işlemin komplikasyonlarını ve etkinliğini değerlendirmektir.

Yöntem: Ağustos 2012 ile Kasım 2015 tarihleri arasında işlem yapılan ardışık 35 hasta çalışmaya dâhil edildi. Hastalara BT ünitesinde, sedasyon anestezisi altında RF jeneratörüne bağlanan elektrot ile ablasyon uygulamas1 yapıldı. Arşiv görüntüler ve dosya kaydı retrospektif olarak incelendi. Lezyonların yerleşim yeri, nidus genişliği ve etkilenen bölge (kortikal, kortikal-intramedüller, medüller) not edildi. İşlem sonrası ağrının kaybolması başarı kriteri olarak kabul edildi. Hastalar rutin olarak işlem sonrası bir gün yatırılarak takip edildi.

Bulgular: Çalışma dâhilinde 25 erkek, $10 \mathrm{kız}$ hasta mevcuttu. Hastaların yaş ortalaması ve nidus ortalama çapı sırasıyla $16 \pm 5.59$ ve $5.64 \pm 2.5 \mathrm{~mm}$ idi. Nidusların 24'ü kortikal, 7'si kortikal-intramedüller, 4'ü medüller bölgede idi. Lezyonlar femur $(n=19)$, tibia $(n=9)$, asetabulum $(n=3)$, fibula $(n=1)$, kalkaneus $(n=1)$, skapula $(n=1)$ ve iliak kemik $(\mathrm{n}=1)$ yerleşimli idi. İşlemi takiben bir hasta hariç tüm hastalarda ağrının kaybolduğu gözlendi. $\mathrm{Bu}$ hastaya 3 hafta sonra re-ablasyon yapıldı. Bir hastada işlem sonrası 1 saat süren peroneal nöropraksi, bir hastada 5-6 gün süren karıncalanma hissi gelişti. Bir hastada 15. ayda yeniden başlayan ağrı (rekürrens) saptandı ve RF ablasyon önerildi. Üç hastada işleme bağlı yanık (üçüncü derece) gelişti.

Sonuç: Osteoid osteomaya yönelik RF ablasyon uygulamalarının tedavi başarısı yüksektir. İşlem başarısızlığı ve rekürrens oranı düşüktür. Tedavi sonrası ağrıda dramatik düzelme, erken taburculuk ve gündelik yaşama kısa sürede dönüş beklenir. Uygun lokalizasyonlardaki lezyonlarda RF ablasyon cerrahi tedavinin önüne geçmiştir. İşleme bağlı komplikasyon oranı düşüktür. Ancak işlem sırasında gelişebilen yanık ciddi bir sorun teşkil etmektedir.
\end{abstract}

Anahtar Kelimeler: BT, Osteoid osteoma, RF ablasyon

\begin{abstract}
Objective: Percutaneous radiofrequency (RF) ablation via computed tomography (CT) guidance has been currently performed in treatment of osteoid osteoma as a popular method. The purpose of this study was to evaluate the complications and efficacy of the procedure.

Methods: A total of thirty-five consecutive patients from August 2012 to November 2015, were included in the study. The ablation procedure was performed under conscious sedation with a RF electrode in tomography unit. Archive images and file records were retrospectively evaluated. Lesions' locations, nidus diameters, and affected areas (cortical, cortical-intramedullary, medullary) were noted. Relief of pain after the procedure was accepted as success criteria. The patients were routinely hospitalized a day after the procedure.

Results: Twenty-five male and ten female patients were included. The mean age and nidus size were $16 \pm 5.59$ and $5.64 \pm 2.5 \mathrm{~mm}$, respectively. Niduses were located in cortical $(\mathrm{n}=24)$, cortical-intramedullary $(\mathrm{n}=7)$, and medullary $(n=4)$ regions. Lesions were located in femur $(n=19)$, tibia $(n=9)$, acetabulum $(n=3)$, fibula $(n=1)$, calcaneus $(n=1)$, scapula $(n=1)$ and iliac bone $(n=1)$. All of the patients except one achieved pain relief after the procedure. The patient, who had pain after ablation, had been re-ablated 3 weeks later. Two patients had peroneal neuropraxia lasting in an hour $(\mathrm{n}=1)$ and tingling sensation lasting in 5-6 days $(\mathrm{n}=1)$ after ablation. Recurrence was recorded in one patient 15 months after the procedure, and re-ablation was offered. Third degree burn associated with ablation procedure was observed in three patients.

Conclusion: RF ablation technique in the treatment of osteoid osteoma has a high success rate. Procedure failure and recurrence rates are lower. Dramatic pain relief, early discharge and return to daily life in a short time are expected. RF ablation is the first-line therapy in appropriate lesion locations. Complication rate is low. However, burn complication, which can occur during the procedure, seems to be a serious problem.
\end{abstract}

Keywords: CT, Osteoid osteoma, RF ablation 


\section{Giriş}

Benign kemik tümörleri, ürettikleri matriks veya maddelere bağlı olarak siniflandirilabilirler. Osteoid osteoma ve osteoblastoma, benign kemik oluşturan tümörlerdir. Osteoid osteoma, tipik olarak çocuklarda özellikle de adölesanlarda görülür. Görülme yaş aralığı 10-35 yaş düzeyidir (1). Küçük nidus yapısına sahiptir(2). Klasik olarak geceleri belirginleşen ağrilara neden olur ve bu ağrıları salisilat analjeziye cevap verir (3). Tüm benign kemik lezyonlarının yaklaşık \%10'unu oluşturur ve erkeklerde 2-4 kat daha siktır (1).

Osteoid osteomaların tanıs1 anamnez, muayene ve radyolojik yöntemler ile yapılabilir. Lezyonun yerleşim yerine göre ek problemler gelişebilir. Bunlara örnek olarak skolyoz, ekstremiteler arasında uzunluk farklılı̆̆ı, eklem efüzyonu, inflamatuar artropati ya da sinovit verilebilir $(1,4,5)$. En sik etkilenen bölge alt ekstremite olup proksimal femur en s1k görüldüğü yerdir. Ancak her kemikte görülebilir. Tibia, femurun geri kalan kesimleri ve omurga diğer sik görülen bölgeleri oluşturur. Tibiada orta diyafizde, vertebralarda lomber bölgede ve ağırlıklı olarak posterior elemanlarda daha siktır. Osteoid osteomalar genellikle kortikal lezyonlardır ancak medüller, subperiosteal ya da intrakapsüler alanlar gibi kemik içinde herhangi bir yerde ortaya çıkabilirler $(1,6,7)$.

Radyolojik değerlendirmede tipik olarak ovoid şekilli olan, genellikle $2 \mathrm{~cm}$ 'den küçük olan nidus yapısı ve sklerotik marjin aranır (1). Direkt grafi, bilgisayarlı tomografi (BT), manyetik rezonans görüntüleme, sintigrafi, uygun lezyonlarda ultrasonografi ve Doppler ultrasonografi inceleme yöntemlerini oluşturur.

Osteoid osteoma tedavisi semptom varlığına bağlıdır. Tolere edilebilen lezyona sahip hastalar ya da non-steroid antienflamatuar ajanlarla kontrol edilebilen lezyonlar takip edilebilir. $\mathrm{Bu}$ lezyonlar zamanla spontan regresyon gösterebilmektedirler $(8,9)$. Semptomatik lezyonlarda tedavi en-blok cerrahi rezeksiyon, aç1k nidus küretaj1 ya da BT rehberliğinde radyofrekans ablasyon ile yapilabilir (10-12).

Çalışmamızda, osteoid osteoma olgularında BT rehberliğinde gerçekleştirilen radyofrekans (RF) ablasyon tedavisi, işlem komplikasyonları ve sonuçlarının tartışılması amaçland.

\section{Gereç ve Yöntem}

\section{Hasta Seçimi}

Ağustos 2012 ile Kasım 2015 tarihleri arasında $\mathrm{BT}$ rehberliğinde $\mathrm{RF}$ ablasyon uygulaması yapılan ardışık 35 hasta çalışmaya dâhil edildi. Hastalara BT ünitesinde, sedasyon anestezisi altında RF jeneratörüne bağlanan elektrot ile ablasyon uygulaması yapıldı. İşlem öncesi tüm hastalar işlem ve olas1 komplikasyonları hakkında bilgilendirilerek onam formu alındı. RF ablasyon uygulamas1 yapılan hastalara ait arşiv görüntüler ve dosya kayd1 retrospektif olarak incelendi. Çalışmamız için kurumumuzdan etik kurul onayı alınd1.

Lezyonların yerleşim yeri, nidus genişliği ve etkilenen bölge (kortikal, kortikalintramedüller, medüller) not edildi. İşlem sonrası ağrının kaybolması başarı kriteri olarak kabul edildi.

\section{BT Rehberliğinde RF Ablasyon Tedavisi}

İşlemler girișimsel radyolog ya da ortopedist tarafından gerçekleştirildi. Hasta uygun pozisyonda BT masasına yatırıldı. BT görüntüsü alınarak lezyonun yeri konfirme edildi. Topraklama pedi, işlem yapılacak lezyon bölgesi göz önüne alınarak sıkı ve doğru bir biçimde hastanın cildine işlem süresince yerleştirildi. Yerleşim yerine göre lezyona en uygun yaklaşım şekli belirlendi. Lezyona dik açı ile yaklaşıma olanak veren en kısa ulaşım mesafesi arandı. Trokarın kaymasını engellemek için dik açı ile yaklaşım tercih edildi. RF ablasyon tedavisi, BT ünitesinde sedasyon anestezisi altında, aseptik koșullar sağlanarak gerçekleștirildi. Giriș yeri işaretlendi ve küçük bir cilt insizyonu açılarak künt diseksiyon yapıldı. Çevre önemli anatomik yapılara zarar vermemek için gerektiğinde karşı normal korteksten giriş yapılarak lezyona ulaşıldı. Trokar ve kanül lezyona ilerletildi. Spot BT görüntüsü alınarak uygun pozisyonda olunup olunmadığ 1 kontrol edildi. Trokarın nidus içinde olduğu görülünce trokar çıkarılıp kanülün içinden elektrot (UniBlade, AngioDynamics, Inc., USA) ilerletildi. Kanülün RF ablasyon elektrotunun yalitımsız aktif ucu ile temasından korunmak için kanül elektrotun aktif ucunu kaplamayacak şekilde $1 \mathrm{~cm}$ ' den daha güvenli 
mesafeye geri çekildi. Elektrot RF jeneratörüne (RITA 1500X, AngioDynamics, Inc., USA) bağlandı. Is1 2-3 dakikada 77 dereceden 90 dereceye çıkarıldı. 90 derecede RF elektrotu ile 4-6 dakika süreyle termal ablasyon uygulandi. İşlem sonrası elektrot ve kanül çıkarılarak yara yeri steril spanç ile kapatıldı. Tüm hastalar rutin olarak işlem sonrası bir gün yatırılarak takip edildi.

\section{İstatistik}

İstatistiksel değerlendirme amacı ile hasta yaşını, cinsiyetini içeren temel veriler ile lezyonun yerleşim yeri, nidus boyutu ve etkilenen bölge bilgisi kullanıldı. Tanımlayıcı istatistik verileri oluşturuldu. İstatistiksel analizler Microsoft Excel ve SPSS yazılımı ile değerlendirildi.

\section{Sonuçlar}

Çalışma dâhilinde 25 erkek, 10 kız hasta mevcuttu. Hastaların yaş ortalaması ve nidus ortalama çap1 sirasiyla $16 \pm 5.59$ ve 5.64 $\pm 2.5 \mathrm{~mm}$ (minimum-maksimum: 1.6-12.3 mm) idi (Tablo 1). Nidusların 24'ü kortikal (Resim 1a), 7'si kortikal-intramedüller (Resim 1b), 4'ü medüller (Resim 1c) bölgede idi. Lezyonlar femur $(n=19)$, tibia $(n=9)$, asetabulum $(n=3)$, fibula $(n=1)$, kalkaneus $(n=1) \quad(\operatorname{Resim} 1 \mathrm{1c})$, skapula $(\mathrm{n}=1)$ ve iliak kemik $(n=1)$ yerleşimli idi. Hastaların ortalama takip süresi $16.14 \pm 10.56$ ay (minimummaksimum: 1-40 ay) idi.

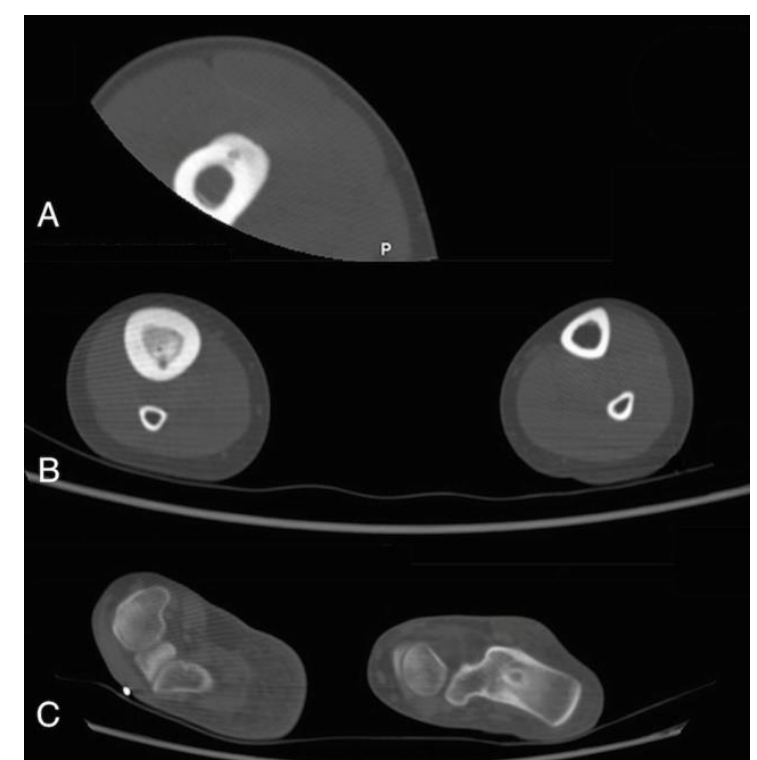

Resim 1: Femurda kortikal (a), sağ tibiada kortikalintramedüller (b) ve sol kalkaneusta medüller (c) bölgede yerleşimli osteoid osteoma nidusları izlenmektedir

İşlemi takiben bir hasta hariç tüm hastalarda ağrının kaybolduğu gözlendi. Ağrıs1 kaybolmayan bu hastaya 3 hafta sonra yapilan re-ablasyonu takiben ağrı şikâyetinin kaybolduğu görüldü. Asetabulum yerleşimli osteoid osteomalı bir hastada işlem sonrası 1 saat sürüp kaybolan peroneal nöropraksi gelişti (Resim 2a-c).

Bir hastada (femur boyun yerleşimli) işlem sonrası 5-6 gün süren karıncalanma hissi gelişti. Bir hastada 15. ayda yeniden başlayan ağr1 (rekürrens) saptand1 ve RF ablasyon önerildi. Üç hastada işleme bağlı cilt yanı̆g 1 (üçüncü derece) gelişti. Bir hastaya debritman ve primer sütürasyon, bir hastaya debritman ve cilt grefti, bir hastaya ise iki kez flep çevirme ve cilt grefti ameliyatı uygulanarak tedavi edildi.

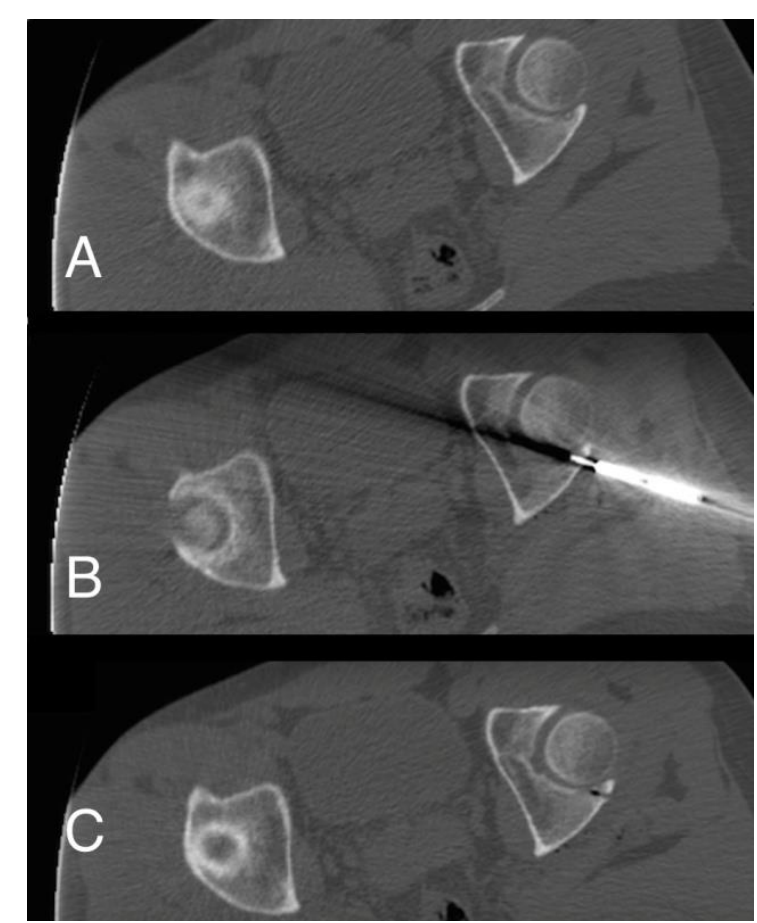

Resim 2: Sol asetabulum arka duvarında yerleșimli osteoid osteoma lezyonu(a), RF ablasyon işlemi (b) ve işlem sonrası kontrol BT görüntüsü (c) izlenmektedir. $\mathrm{Bu}$ hastada işlem sonrası 1 saat sürüp kaybolan peroneal nöropraksi gelişti.

Lezyonların 30'una lezyon tarafindaki korteksten, 5'ine karşı korteksten medulla geçilerek ulaşıldı (Resim 3a-c). 
Tablo 1. RF Ablasyon tedavisi uygulanan hastalara ait cinsiyet, yaş, lezyon tarafi, yerleşim yeri ve bölgesi ile nidus çapları gösterilmektedir.

\begin{tabular}{|c|c|c|c|c|c|}
\hline Cinsiyet & Yaş & Taraf & Lezyon Yeri & Nidus Bölgesi & Nidus Çapı \\
\hline $\mathrm{E}$ & 19 & Sağ & Femur Orta Diafiz & Kortikal & 3,8 \\
\hline $\mathrm{K}$ & 13 & Sağ & İliak Kemik & Kortikal & 6,9 \\
\hline $\mathrm{E}$ & 18 & Sol & FemurTrokanter Minör & Kortikal+İntramedüller & 10 \\
\hline $\mathrm{E}$ & 17 & Sağ & FemurProksimalDiafiz & Kortikal & 3,5 \\
\hline E & 15 & Sağ & TibiaProksimalMetafiz & Kortikal+İntramedüller & 7,9 \\
\hline $\mathrm{K}$ & 7 & Sağ & Femur Orta Diafiz & Kortikal & 4,6 \\
\hline $\mathrm{K}$ & 8 & Sağ & Femur Boyun & Kortikal & 7,9 \\
\hline E & 14 & Sol & FemurProksimalDiafiz & Kortikal & 5 \\
\hline $\mathrm{E}$ & 14 & Sağ & TibiaProksimalDiafiz & İntramedüller & 9,2 \\
\hline E & 12 & Sağ & TibiaProksimalDiafiz & Kortikal+İntramedüller & 6,9 \\
\hline $\mathrm{K}$ & 16 & Sağ & FibulaDistalDiafiz & Kortikal & 1,6 \\
\hline $\mathrm{E}$ & 13 & Sağ & Tibia Orta Diafiz & Kortikal & 5,9 \\
\hline E & 10 & Sağ & Femur Boyun & Kortikal & 4,5 \\
\hline $\mathrm{K}$ & 15 & Sol & Kalkaneus & İntramedüller & 5,8 \\
\hline E & 14 & Sağ & Femur Boyun & Kortikal & 4,4 \\
\hline E & 22 & Sol & Skapula & Kortikal+İntramedüller & 12,3 \\
\hline E & 14 & Sağ & TibiaMetafizodiafizer & Kortikal & 4,6 \\
\hline $\mathrm{E}$ & 23 & Sol & Femur Boyun & Kortikal & 4,5 \\
\hline $\mathrm{E}$ & 29 & Sol & FemurProksimalDiafiz & Kortikal & 3,8 \\
\hline $\mathrm{K}$ & 13 & Sol & FemurTrokanter & Kortikal & 6,8 \\
\hline $\mathrm{E}$ & 15 & Sağ & FemurSubtrokanterik & Kortikal & 5,5 \\
\hline K & 6 & Sağ & Femur Boyun & Kortikal+İntramedüller & 5,8 \\
\hline E & 23 & Sağ & FemurProksimalDiafiz & Kortikal & 3,8 \\
\hline E & 19 & Sağ & FemurProksimalDiafiz & Kortikal & 4 \\
\hline $\mathrm{E}$ & 18 & Sol & TibiaDistalDiafiz & Kortikal & 3,6 \\
\hline $\mathrm{E}$ & 11 & Sağ & Tibia Orta Diafiz & Kortikal+İntramedüller & 5,7 \\
\hline $\mathrm{E}$ & 18 & Sol & TibiaDistalDiafiz & Kortikal & 3,6 \\
\hline $\mathrm{E}$ & 31 & Sol & Asetabulum & Kortikal & 5,4 \\
\hline K & 25 & Sağ & Femur Orta Diafiz & Kortikal & 4,4 \\
\hline $\mathrm{K}$ & 10 & Sağ & Asetabulum & Kortikal+İntramedüller & 10,4 \\
\hline E & 16 & Sol & Tibia Orta Diafiz & Kortikal & 2,6 \\
\hline $\mathrm{E}$ & 14 & Sağ & Femur Orta Diafiz & İntramedüller & 4,4 \\
\hline $\mathrm{E}$ & 15 & Sol & FemurSubtrokanterik & Kortikal & 3,2 \\
\hline $\mathrm{E}$ & 19 & Sağ & FemurProksimalDiafiz & Kortikal & 4,1 \\
\hline $\mathrm{K}$ & 14 & Sağ & Asetabulum & İntramedüller & 11 \\
\hline
\end{tabular}

\section{Tartışma}

Günümüzde gelişen teknoloji sonucunda osteoid osteomalı hastaların tedavisinde cerrahi tedavi yerine hastanede kalıș süresini azaltan, daha az komplikasyon oranına sahip RF ablasyon gibi girişimsel yöntemler gelişmeye ve kullanılmaya 
başlamıştır. Osteoid osteoma da BT rehberliğinde uygulanabilen RF ablasyon tedavisinin gelişimi ile ilk olarak tanımlandığı 1989 (13) yllından bu yana girişimsel olarak tedavi edilebilen, cerrahiye alternatif yöntem bulunabilmiş lezyonlardan birisidir (14). Bu çalışmada, BT rehberliğinde gerçekleştirdiğimiz RF ablasyon tedavisinin etkinliğinin yüksek olduğunu, gündelik yaşama kısa sürede dönüşe olanak verdiğini ancak işleme bağlı gelişebilen cilt yanığının ciddi bir komplikasyon olduğunu gördük.

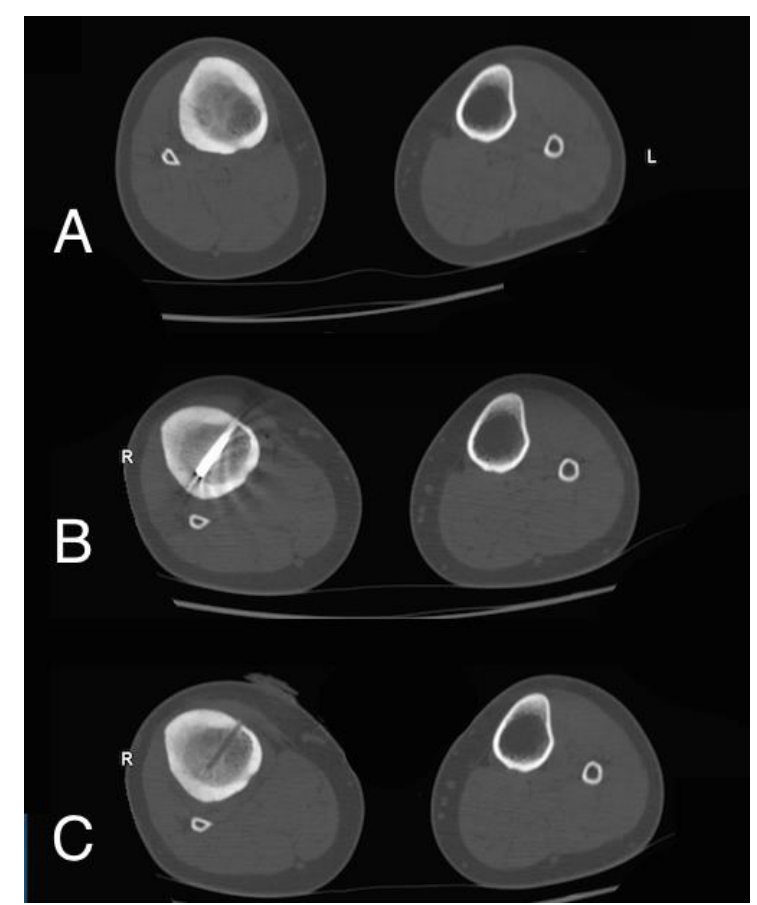

Resim 3: Sağ tibiada yerleşimli osteoid osteoma lezyonu (a), karşı medial korteksten ilerletilen RF ablasyon elektrotu (b) ve işlem sonrası kontrol BT görüntüsü (c) izlenmektedir.

Osteoid osteomalar genellikle kortikal bölgede bulunan lezyonlardır. Ancak kemikte medulla, subperiosteal ve intrakapsüler alanlar gibi herhangi bir yerde de ortaya çıkabilirler. Ayrıca nidusu çevreleyen sklerozun da reaktif olduğu ve lezyonun kendisini yansitmadiğ1 unutulmamalıdır (1). Çalışmamızda lezyonlar nidusunun bulunduğu bölgeye göre değerlendirildiğinde 35 lezyonun 24'ünün kortikal, 7'sinin kortikal-intramedüller ve 4'ünün medüller bölgelerde olduğu görüldü.

Osteoid osteomalar vücutta her kemikte bulunabilmekle birlikte en sik proksimal femurda saptanırlar. Tibia tutulumu var ise orta diyafizde, vertebra tutulumu var ise lomber bölgede ve ağırlıklı olarak posterior elemanlarda daha siktır(7). Hasta grubumuzda da lezyonların çoğunun femur yerleşimli olduğu (n=19) görülmüştür. Ayrıca tibia $(n=9)$, asetabulum $(n=3)$, fibula $(n=1)$, kalkaneus $(n=1)$, skapula $(n=1)$ ve iliak kemik $(n=1)$ yerleşimli lezyonlarda da RF ablasyon tedavisi yapılmıştır.

BT rehberliğinde RF ablasyon işlemini lokal anestezi altında (14), derin sedasyon eşliğinde (15), spinal anestezi (11)ve genel anestezi altında (özellikle çocuk hastalarda) $(15,16)$ yaptığını belirten yazarlar bulunmaktadır. Çalışma grubumuzdaki tüm hastalarda RF ablasyon uygulaması derin sedasyon anestezisi altındabaşarı ile gerçekleştirilmiştir.

Osteoid osteomada RF ablasyon tedavisinin başarı oranı yüksektirve dünya genelinde popularitesi artmıştır (11). Sadece bir hastamızda işlemi takiben ağrının kaybolmadığı görüldü. $\mathrm{Bu}$ hastaya 3 hafta sonra yapılan re-ablasyonu takiben ağr1 şikâyeti kayboldu (Resim 4a-c). Bu hastada ilk ablasyon uygulamas1 sirasinda nidusun tedavi edilememe nedeni, korteksin kalınlaşmış olmas1 ve bu nedenle elektrotun nidusun hafif uzağında kalmış olması şeklinde değerlendirildi. Kalın korteks nedeni ile nidusa ulaşımın zor olduğu olgularda ablasyon öncesi korteks drillenerek nidusa daha kolay ulaşım için yol açılabilir.

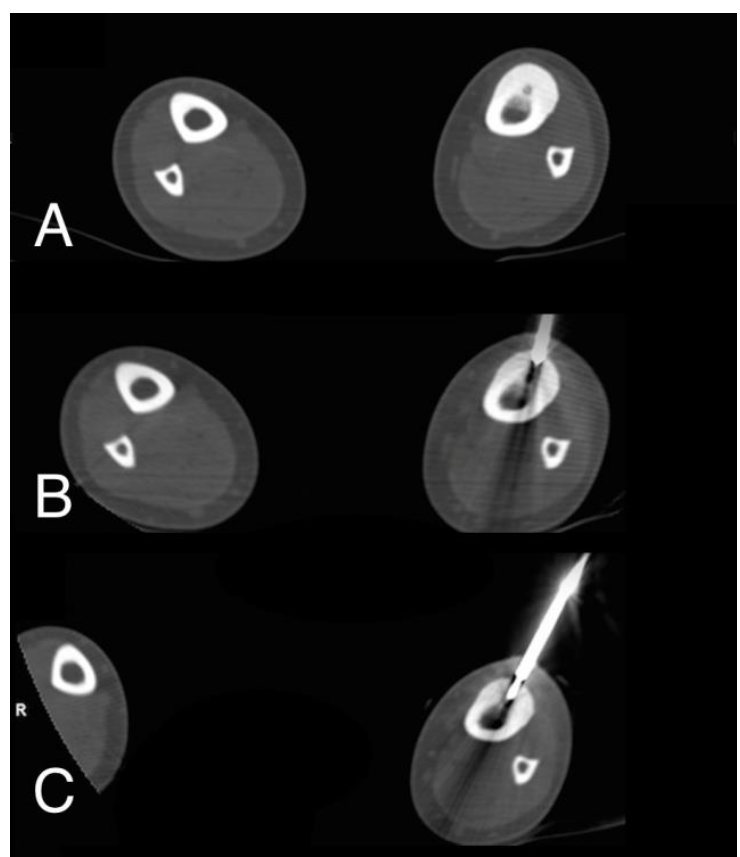

Resim 4: Sol tibia anterior kortekste belirgin kalınlaşmaya neden olan osteoid osteoma lezyonu (a) izlenmektedir. İlk RF ablasyon uygulaması (b) 
sonrası ağrısı kaybolmayan bu hastaya 3 hafta sonra yapılan re-ablasyon işlemini (c) takiben ağrı şikâyeti kayboldu.

Osteoid osteomada rekürrens en-blok rezeksiyon sonras1 nadirdir. Küretaj ile tedavi edilenlerde rezeksiyona kıyasla hafif yüksektir (17). Rekürrensin özellikle birden fazla nidusa sahip lezyonlarda inkomplet rezeksiyona bağlı olduğu düşünülmektedir $(18,19)$. Son zamanlarda BT rehberliğinde RF ablasyon tedavisi güvenilir ve efektif, minimal invaziv bir yöntem olarak ve birçok klinik merkezde osteoid osteomada ilk tedavi yöntemi olarak tercih edilmektedir. RF ablasyon tedavisinin klinikbaşarı oranı \%76-100 aralığındadır (10). Osteoid osteomada rekürrensler re-eksizyon ya da ablasyon ile başarnyla tedavi edilebilir. Rezidü semptomatik tümör varlığında reablasyon daha başarılı iken, ağrısız interval sonrası nüks geliştiğinde ablasyon daha az başarılıdır (20). Çalışma grubumuzdaki bir hastada 15. ayda yeniden başlayan ağrı (rekürrens) saptandı ve RF ablasyon ile tedavi önerildi.

Osteoid osteomada RF ablasyon tedavisinin komplikasyon oranı düşüktür. Önceki çalışmalarda cilt yanığı, fraktür, osteomyelit, vazomotor instabilite, tendinit ve muskuler hematom komplikasyonları bildirilmiştir (12, 14-16, 21). Hasta grubumuzda işleme bağlı olarak gelişen komplikasyonları şöyle sıralayabiliriz: Asetabulum yerleşimli osteoid osteomalı bir hastada işlem sonrası 1 saat sürüp kaybolan peroneal nöropraksi gelişti. Femur boynu yerleşimli lezyona sahip bir hastada işlem sonras1 5-6 gün süren karıncalanma hissi gelişti. Üç hastada ise üçüncü derece yanık geliştiği görüldü.

RF ablasyon tedavisi sırasında gelişen işlem bölgesindeki cilt yanıklarının elektrotun yalıtımındaki defektten kaynaklandığı düşünülmektedir. Kanülün $\mathrm{RF}$ ablasyon elektrotunun yalitımsiz aktif ucu ile temasından korunmak için kanülün elektrotun aktif ucunu kaplamayacak şekilde $1 \mathrm{~cm}$ den daha güvenli mesafeye geri çekilmesi önemlidir. Biyopsi kanülünün geri çekilmesi sırasında elektrotun yalitımına zarar verme olasılığ da mevcuttur. Elektrotun metal kanüle teması 1sınmaya ve işlem bölgesinde üçüncü derece cilt ve yumuşak doku yanığına neden olmaktadır(22). Hastanın uyluk veya bacak bölgelerine bağlanan topraklama pedi bölgesinde, k1lavuz kenar ya da ped köşesindeki cilt yanıkları ise pedin cilt ile zayıf teması, kablo devresindeki kırıklar ve ped dizaynı ile ilgili problemler yüzündendir (23). Ancak literatürde herhangi bir neden gösterilememiş olgu sunumları da mevcuttur (21). Çalışmamızda üç hastada işleme bağlı yanık (üçüncü derece) gelişti. Bunlardan ikisi iğne giriş bölgesi üzerindeydi (Resim 5a-b) ve biri debridman ve primer sütürasyon ile, diğeri iki kez flep çevirme ve cilt grefti ameliyatı uygulanarak tedavi edildi. Üçüncü hastada yanık, topraklama pedi hemen proksimalinde kaydedildi (Resim 6a-b). Bu hastanın tedavisi debritman ve cilt grefti ile yapıldı. Yapılan değerlendirmelerde bu üç yanık olgusu için de işlemlerin uygun şekilde yapılmış olduğu görüldü. Yanığa sebep olan gerçek neden bulunamadi.

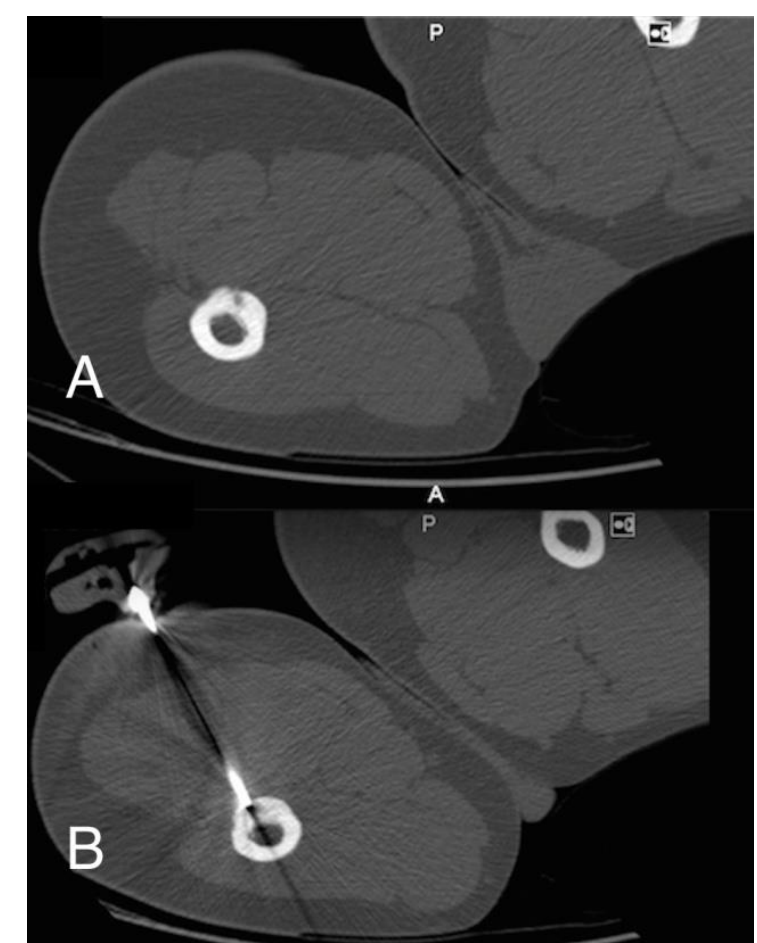

Resim 5: Să̆ femurda osteoid osteoma lezyonu (a) ve RF ablasyon işlemine ait BT görüntüsü (b) izlenmektedir. $\mathrm{Bu}$ hastada iğne giriş bölgesi üzerinde üçüncü derece yanık gelişti.

Literatür 1şığında değerlendirildiğinde mevcut topraklayıcı ped teknolojisi ve dizaynının RF gücünü daha fazla artırmak için sınırlayıcı bir faktör olduğu görülmektedir. Monopolar sistemler RF döngüsünü tamamlamak için topraklama pedi kullanırlar. Aynı miktarda enerji cilt pedinde olduğu gibi elektrotun 
ucunda toplanır. Kılavuz kenar maksimum güç konsantrasyonu alanıdır. Topraklama pedi bölgesindeki termal hasar güncel ve daha güçlü sistemlerde artan sıklıkla rapor edilmektedir. Cilt 1sınmasını azaltmak için önerilen yöntemler mevcuttur. Topraklayıcı pedin yüzey alanını genişletmek, pedlerin sayısını artırmak, cilt altındaki sıcaklığı ölçebi-

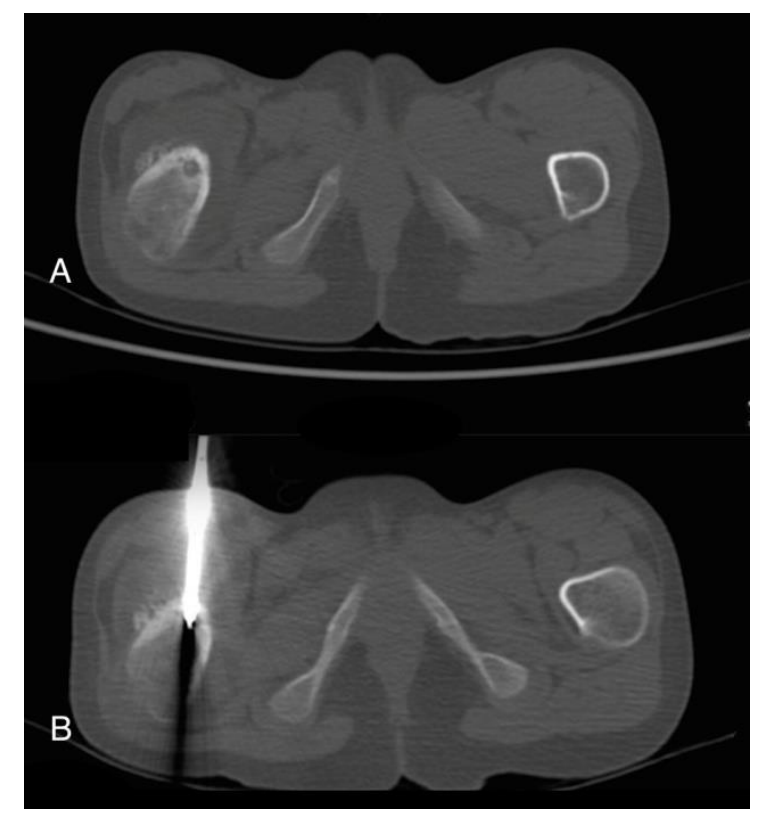

Resim 6a,b: Sağ proksimal femurda yerleşimli osteoid osteoma lezyonu (a) ve RF ablasyon işlemine ait BT görüntüsü (b) izlenmektedir. İşlem sonrasında, bu hastada krural bölgeye yerleştirilen topraklama pedinin proksimalinde, sağ diz altı düzeyde abrazyon ve renk değişikliği saptandı.

len elektrot kullanmak ve pedlerde sekansiyel aktivasyon kullanmak şeklindeki uygulamalar ile iyi sonuçlar rapor edilmiştir $(21,24,25)$. Ayrıca anterior tibia gibi özellikle ciltaltı yumuşak doku kalınlığının az olduğu bölgelerde olmak üzere işlem sirasında profilaktik olarak kanül giriş bölgesi çevresine soğuk uygulaması da yapılabilir $(22,15,26)$. Alternatif ve daha güvenli bir yöntem olarak navigasyonel bipolar RF ablasyon sistemi de, ped gerektirmemesi, lezyon periferinde 1sıtakibiyle güvenli ve daha kisa sürede ablasyona olanak vermesi ve navigasyonla daha geniş alanda tek girişle ablasyon sağlayabilmesinedeniyle tercih edilebilir (27).

Osteoid osteomada radyofrekans ablasyon dışındaki perkütan ablasyon tekniklerialkol enjeksiyonunu $(28,29)$ ve interstisyel lazer fotokoagülasyonu (30) içermektedir. Alkol enjeksiyonunun dezavantaj1 doku üzerine non-selektif etki göstermesi ve ekstravaze olan alkolün çevre normal dokuyu etkilemesi olarak tanımlanmıştır. Lazer fotokoagülasyon oldukça pahalidır ve gerekli vakalarda simultane biyopsi yapılamamaktadır(16).

Karaciğer tümörlerinin tedavisinde de birçok merkezde uygun lezyonlarda primer ablasyon yöntemi olarak RF ablasyon uygulanmaktadır (31). RF ablasyon ile osteoid osteoma olgularında olduğu gibi hepatosellüler karsinom (HCC) lezyonlarında da tedavi başarısı yüksektir. HCC lezyonlarında RF ablasyonla, Livraghi ve arkadaşlarının serisinde \%90.4 ve Shiratove arkadaşlarının serisinde \%93.3 tam yanıt görülmüştür (32, 33). Osteoid osteomada RF ablasyon tedavisinin klinik başarı oranı \%76-100 aralığındadır (10).

Sonuç olarak, osteoid osteomaya yönelik RF ablasyon uygulamalarının tedavi başarısı yüksektir. İşlem başarısızlığı ve rekürrens oranı düşüktür. Tedavi sonrası ağrıda dramatik düzelme, erken taburculuk ve gündelik yaşama ağrısız olarak kısa sürede geri dönebilme beklenir. Osteoid osteoma tedavisinde uygun lokalizasyonlardaki lezyonlarda RF ablasyon cerrahi tedavinin önüne geçmiştir. İşleme bağlı komplikasyon oranı düşüktür. Ancak işlem sırasında işleme bağlı olarak gelişebilen yanık ciddi bir sorun teşkil etmektedir.

\section{Çıkar Çatışması: Yok}

\section{Kaynaklar}

1. Greenspan A, Jundt G, Remagen W. Bone-Forming (Osteogenic) Lesions. In: Greenspan A, Jundt G, Remagen W, eds. Differential Diagnosis in Orthopaedic Oncology (2nd ed). Philadelphia; Lippincott Williams \& Wilkins; 2007:2;59-74

2. Springfield DS, Gebhardt MC. Bone and soft tissue tumors. In: Morrissy RT, Weinstein SL, eds. Lovell and Winter's Pediatric Orthopaedics (6th ed). Philadelphia; Lippincott Williams \& Wilkins; 2006:493

3. Papathanassiou ZG, Megas P, Petsas T, et al. Osteoid osteoma: diagnosis and treatment. Orthopedics. 2008;31:1118

4. Kaweblum M, Lehman WB, Bash J, et al. Diagnosis of osteoid osteoma in the child. Orthop Rev 1993;22:1305

5. Schlesinger AE, Hernandez RJ. Intracapsular osteoid osteoma of the proximal femur: findings on plain film and CT. AJR Am J Roentgeno. 1990;154:1241-4 
6. Horvai A, Klein M. Osteoid osteoma. In: Fletcher CD, Bridge JA, Hogendoorn PC, Mertens F, eds. WHO Classification of Tumours of Soft Tissue and Bone (4th ed). Lyons; International Agency for Research on Cancer; 2013:277

7. Unni KK, Inwards CY. Dahlin's bone tumors, general aspects and data on 10,165 cases (6th ed). Philadelphia; Lippincott Williams \& Wilkins; 2009:9;102-12

8. Feletar M, Hall S. Osteoid osteoma: a case for conservative management. Rheumatology 2002;41:585-6

9. Kneisl JS, Simon MA. Medical management compared with operative treatment for osteoidosteoma. J Bone Joint Surg Am 1992;74:179

10. Cantwell CP, Obyrne J, Eustace S. Current trends in treatment of osteoid osteoma with an emphasis on radiofrequency ablation. Eur Radiol 2004;14:607-617

11. Cioni R, Armillotta N, Bargellini I, et al. CT-guided radiofrequency ablation of osteoid osteoma: long term results. Eur Radiol 2004;14:1203-8

12. Earhart J, Wellman D, Donaldson J, et al. Radiofrequency ablation in the treatment of osteoid osteoma: results and complications. Pediatr Radiol 2013;43:814

13. Tillotson CL, Rosenberg AE, Rosenthal DI. Controlled thermal injury of bone. Report of a percutaneous technique using radiofrequency electrode and generator. Invest Radiol 1989;24:88892

14. Çakar M, Esenyel CZ, Seyran M, et al. Osteoid osteoma treated with radiofrequency ablation. Adv Orthop 2015; 2015:807274. DOI: $10.1155 / 2015 / 807274$

15. Hoffmann RT, Jacobs TF, Kubisch CH, Trumm CG, Weber C, Duerr HR, Helmberger TK, Reiser MF. Radiofrequency ablation in the treatment of osteoid osteoma-5-year experience. Eur J Radiol 2010;73:374-9

16. Yip PS, Lam YL, Chan MK, Shu JS, Lai KC, So YC. Computed tomography-guided percutaneous radiofrequency ablation of osteoid osteoma: local experience. Hong Kong Med J 2006;12:305-9

17. Sluga $M$, Windhager $R$, PfeifferM, DominkusM, Kotz R. Peripheral osteoid osteoma. Is there still a place for traditional surgery? J Bone Joint Surg $(\mathrm{Br})$ 2002;84:249-51

18. Allieu Y, Lussiez B, Benichou M, Cenac P. A double nidus osteoid osteoma in a finger. $\mathrm{J}$ Hand Surg 1989;14:538-41

19. Sampath SC, Sampath SC, Rosenthal DI. Serially recurrent osteoid osteoma. Skeletal Radiol 2015;44:875-81

20. Motamedi D, Learch TJ, Ishimitsu DN, et al. Thermal Ablation of Osteoid Osteoma: Overview and Step-byStep Guide. RadioGraphics 2009;29:2127-41)
21. Huffman SD, Huffman NP, Lewandowski RJ, Brown DB. Radiofrequency ablation complicated by skin burn. Semin Intervent Radiol 2011;28:179-82

22. Widmann G, Jaschke W, Bale R. Case report: Thirddegree skin and soft tissue burn after radiofrequency ablation of an osteoid osteoma guided through a triple-crown biopsy cannula. Skeletal Radiol 2012;41:1627-30

23. Steinke K, Gananadha S, King J, Zhao J, Morris DL. Dispersive pad site burns with modern radiofrequency ablation equipment. Surg Laparosc Endosc Percutan Tech. 2003;13:366-71

24. Schutt DJ, Swindle MM, Bastarrika GA, Haemmerich D. Sequential activation of ground pads reduces skin heating during radiofrequency ablation: initial in vivo porcine results. Conf Proc IEEE Eng Med Biol Soc. 2009;2009: 4287-90

25. Thiagalingam A, Pouliopoulos JM, Barry MA, et al. A thermochromic dispersive electrode can measure the underlying skin temperature and prevent burns during radiofrequency ablation. J Cardiovasc Electrophysiol. 2005;16:781-88

26. Pinto $\mathrm{CH}$, Taminiau $\mathrm{AH}$, Vanderschueren GM, Hogendoorn PC, Bloem JL, Obermann WR. Technical considerations in CT-guided radiofrequency thermal ablation of osteoid osteoma: tricks of the trade. AJR. 2002;179:1633-42

27. Wallace AN, Tomasian A, Chang RO, Jennings JW. Treatment of Osteoid Osteomas Using a Navigational Bipolar Radiofrequency Ablation System. Cardivasc Intervent Radiol 2016;39:768-772)

28. Adam G, Keulers P, Vorwerk D, Heller KD, Fuzesi L, Guenther RW. The percutaneous CT-guided treatment of osteoid osteoma: a combined procedure with a biopsy drill and subsequent ethanol injection [in German]. Rofo. 1995;162:232-5

29. Sanhaji L, Gharbaoui IS, Hassani RE, Chakir N, Jiddane M, Boukhrissi N. A new treatment of osteoid osteoma: percutaneous sclerosis with ethanol under scanner guidance [in French]. J Radiol 1996;77:37-40

30. Witt JD, Hall-Craggs MA, Ripley P, Cobb JP, Bown SG. Interstitial laser photocoagulation for the treatment of osteoid osteoma. J Bone Joint Surg Br. 2000;82:1125-8

31. Arıbaş $B K$. Karaciğer malign tümörlerinde perkütan radyofrekans (RF) ablasyon. Güncel Gastroenteroloji 2009;13:81-88)

32. Livraghi T, Goldberg SN, Lazzaroni S, et al. Small hepatocellular carcinoma: Treatment with radiofrequency ablation versus ethanol injection. Radiology 1999;210:655-61

33. Shirato K, Morimoto M, Tomita $N$, et al. Small hepatocellular carcinoma: Therapeutic effectiveness of percutaneous radiofrequency ablation therapy with a LeVeen needle electrode. J Ultrasound Med 2002;21:67-76) 